\title{
Nanostructured Plasma Polymerized Fluorocarbon Films for Drop Coating Deposition Raman Spectroscopy (DCDRS) of Liposomes
}

\author{
Alžbeta Kuižová ${ }^{1}\left(\right.$, Anna Kuzminova ${ }^{2}$, Ondřej Kylián ${ }^{2, *}$ and Eva Kočišová ${ }^{1, *}$ \\ 1 Faculty of Mathematics and Physics, Institute of Physics, Charles University, Ke Karlovu 5, \\ 12116 Prague 2, Czech Republic; betka.kuizova@gmail.com \\ 2 Department of Macromolecular Physics, Faculty of Mathematics and Physics, Charles University, \\ V Holešovičkách 2, 18000 Prague 8, Czech Republic; annakuzminova84@gmail.com \\ * Correspondence: Ondrej.Kylian@mff.cuni.cz (O.K.); Eva.Kocisova@mff.cuni.cz (E.K.); \\ Tel.: +420-951552258 (O.K.); +420-951551349 (E.K.)
}

check for updates

Citation: Kuižová, A.; Kuzminova, A.; Kylián, O.; Kočišová, E.

Nanostructured Plasma Polymerized

Fluorocarbon Films for Drop Coating Deposition Raman Spectroscopy (DCDRS) of Liposomes. Polymers 2021, 13, 4023. https://doi.org/ $10.3390 /$ polym 13224023

Academic Editor: Johannes Carolus (John) Jansen

Received: 15 October 2021

Accepted: 15 November 2021

Published: 21 November 2021

Publisher's Note: MDPI stays neutral with regard to jurisdictional claims in published maps and institutional affiliations.

Copyright: (c) 2021 by the authors. Licensee MDPI, Basel, Switzerland. This article is an open access article distributed under the terms and conditions of the Creative Commons Attribution (CC BY) license (https:// creativecommons.org/licenses/by/ $4.0 /)$.

\begin{abstract}
Raman spectroscopy is one of the most used biodetection techniques. However, its usability is hampered in the case of low concentrated substances because of the weak intensity of the Raman signal. To overcome this limitation, the use of drop coating deposition Raman spectroscopy (DCDRS), in which the liquid samples are allowed to dry into well-defined patterns where the non-volatile solutes are highly concentrated, is appropriate. This significantly improves the Raman sensitivity when compared to the conventional Raman signal from solution/suspension. As DCDRS performance strongly depends on the wetting properties of substrates, we demonstrate here that the smooth hydrophobic plasma polymerized fluorocarbon films prepared by magnetron sputtering (contact angle $108^{\circ}$ ) are well-suited for the DCDRS detection of liposomes. Furthermore, it was proved that even better improvement of the Raman signal might be achieved if the plasma polymer surfaces are roughened. In this case, $100 \%$ higher intensities of Raman signal are observed in comparison with smooth fluorocarbon films. As it is shown, this effect, which has no influence on the profile of Raman spectra, is connected with the increased hydrophobicity of nanostructured fluorocarbon films. This results in the formation of dried liposomal deposits with smaller diameters and higher preconcentration of liposomes.
\end{abstract}

Keywords: drop coating deposition Raman spectroscopy; DCDRS; plasma polymers; liposomes; nanostructured surfaces; wettability

\section{Introduction}

The wetting of polymeric surfaces plays a crucial role in different sectors such as the textile industry [1], ink-jet printing [2], metallization of polymers [3], and last but not least in biomedical applications $[4,5]$. The latter is connected with the fact that the surface wettability governs the interaction of polymers with surrounding media, including the biological suspensions or solutions. This, in turn, influences the attachment, adhesion, or the proliferation of cells or adsorption of biomolecules on polymeric surfaces [6-9]. In addition, in some situations, the wettability per-se is not the only parameter to be considered. Equally, and in some cases an even more important parameter, is the way in which a liquid drop dries on a surface. As demonstrated in numerous studies, the droplet drying dynamics have a strong impact on the formation of stains after the complete evaporation of droplets that contain non-volatile solutes [10-12]. A prominent example of this is the formation of the so-called "coffee-ring", i.e., the ring-shaped pattern where the edge part comprises accumulated non-volatile solutes [13]. Such structures are highly advantageous, especially for biodetection, as the substances to be detected are highly preconcentrated in well-defined surface locations. One of the biodetection techniques that benefit from the 
"coffee-ring" formation is the drop coating deposition Raman spectroscopy (DCDRS). In this technique, the Raman signal is acquired from a dried ring pattern where the analyte is highly preconcentrated, which allows the detection and identification of molecules in small volumes (a drop of several $\mu \mathrm{L}$ ) and at low concentrations $(\mathrm{mM}-\mu \mathrm{M})$. Furthermore, the great advantage of this approach is the possibility of detecting biological samples at biologically relevant concentrations, which is not possible by conventional Raman spectroscopy (measurement from solutions or suspensions at a standard concentration from cuvette). Previous works showed improvement by $10^{3}-10^{5}$ orders of magnitude as compared to the detection sensitivity of conventional Raman spectroscopy from solutions of proteins [14,15], porphyrins [16] or suspensions of liposomes $[17,18]$. The DCDRS method was also successfully employed in the detection of dipicolinic acid [19], oligosaccharides [20], food and environmental contaminants [21] and also in a study of real body samples as human tears [22-24]. These past studies were concerned about determining the lowest possible detected concentration and finding the spectral fingerprint of protein composition for the tear samples. In addition, the DCDRS technique was shown to be applicable to monitor processes such as albumin glycation [25], catalyzed oxidation [26], and amino acid and peptide phosphate protonation [27] or segregation of impurities and components in mixed solutions [28-30]. As for using Raman spectroscopy to study biological samples, it is inevitable to employ a method that can be sensitive even in low concentrations and small volumes. This makes the DCDRS technique an interesting alternative to the more often employed surface-enhanced Raman spectroscopy (SERS) that relies on substrates with precisely designed metal or metal oxide nanostructures (e.g., [31-33]).

DCDRS technique proved itself a versatile tool for a broad range of applications, mainly because of its sensitivity to low concentrated samples compared to conventional Raman spectroscopy. Nevertheless, we believe that this sensitivity could be further improved because, despite its simplicity, the applicability of DCDRS is strongly dependent on the used substrate material. It has to be highly hydrophobic to provide as low a diameter of the formed stain as possible to reach the highest preconcentration of the analyte and assure the reliable formation of well-defined rings needed for the DCDRS measurements. For instance, three types of smooth substrates (commercial Teflon-coated stainless steel surface SpecTRIM from Tienta Sciences (Indianapolis, IN, USA), non-commercial polished $\mathrm{CaF}_{2}$, and silanized glass surfaces) were tested and compared in a recent study [34]. This comparison revealed significant variation in the Raman signal enhancement in dependence on the wettability of employed surfaces (the hydrophobicity was different because of the different chemical composition/used materials): the highest signal enhancement was observed for fluorocarbon surfaces that exhibited the highest water contact angle. Therefore, we have focused our attention on the fluorocarbon (C:F) surfaces.

The aim of this study is to demonstrate the possibility to enhance further the DCDRS detection capability of fluorocarbon surfaces by their nanostructuring that results in the increase in the surface hydrophobicity. The nanostructured surfaces were used here for the first time since all the previous DCDRS works employed only the smooth ones [14-30]. To meet this general aim, smooth C:F and nanoroughened C:F surfaces with invariant chemical composition were produced using a fully solvent-free plasma-based deposition strategy that combines radio frequency magnetron sputtering of polytetrafluoroethylene target and gas-phase synthesis of $\mathrm{Cu}$ nanoparticles. As will be shown, this allows to precisely tailor the roughness and wettability of produced coatings. The DCDRS performance of produced surfaces was subsequently compared using liposome suspension selected as a model biological system.

\section{Materials and Methods}

\subsection{Fabrication of DCDRS Substrates and Their Characterization}

To evaluate the role of surface roughness of fluorocarbon (C:F) thin films on the DCDRS performance, two types of surfaces with identical surface chemical composition were produced-(i) smooth and (ii) roughened. The smooth C:F films were produced by 
magnetron sputter deposition of $40 \mathrm{~nm}$ thick polytetrafluoroethylene (PTFE) layer onto the base platform - one side polished Si wafers (ON Semiconductor, cleaned in ethanol and water) in our case. These substrates are denoted as PPTFE in the subsequent text. The tailor-made roughness of C:F coatings was achieved following a procedure introduced in [35]. This strategy, which is schematically depicted in Figure 1, relies on the additional deposition step, in which the controlled number of nanoparticles (Nps) are sandwiched between two C:F layers (both $20 \mathrm{~nm}$ thick in this study). The required surface roughness of resulting coatings is then reached simply by adjusting the size [36] and the number of Nps embedded in the C:F layer [37]. The Cu Nps were deposited in this study utilizing a Haberland-type gas aggregation source (GAS) [38]. It was based on the direct current (DC), water-cooled, 3-inch planar magnetron equipped with a $\mathrm{Cu}$ target, which was placed into the water-cooled aggregation chamber (inner diameter of $100 \mathrm{~mm}$ ) and terminated by a conical output orifice (diameter of $1.5 \mathrm{~mm}$ ). The GAS was attached to the main deposition chamber, which was pumped by rotary and diffusion pumps. The $\mathrm{Cu}$ Nps are produced using $\mathrm{Ar}$ as a working gas at the pressure of $40 \mathrm{~Pa}$ in the aggregation chamber and using the magnetron current of $400 \mathrm{~mA}$. The deposition time of $\mathrm{Cu}$ Nps was 2 and $4 \mathrm{~min}$, and the corresponding samples are denoted as $\mathrm{NpsCu} 2$ and $\mathrm{NpsCu} 4$, respectively.

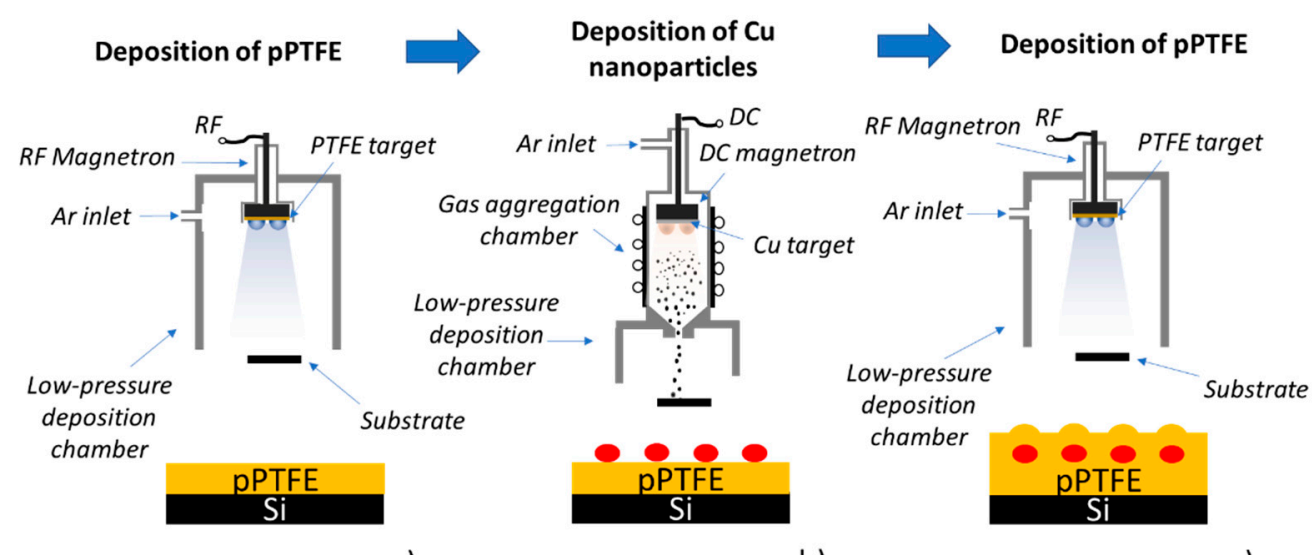

a)

b)

c)

Figure 1. (a) Deposition of pPTFE layer. (b) Deposition of Cu nanoparticles. (c) Overcoating Cu Nps with pPTFE film.

The surface morphology of fabricated coatings was determined by means of atomic force microscopy (AFM) and scanning electron microscopy (SEM). The AFM measurements (scanned area $10 \mu \mathrm{m} \times 10 \mu \mathrm{m}$ ) were performed using a QuesantQ-Scope $350 \mathrm{AFM}$. The AFM scans were acquired in the semi-contact mode (scan rate $2 \mathrm{~s}$ ) using ACLA-10 Si probes (tip radius $<10 \mathrm{~nm}$, AppNano, Mountain View, CA, USA). The AFM images were subsequently analyzed by open-source Gwyddion software. SEM analysis of the produced coatings was done employing the scanning electron microscope JSM 7200F (JEOL, Akišima, Japan). The SEM images were measured in both secondary electron (SE) and back-scattered electron (BE) modes using an accelerating voltage of $15 \mathrm{kV}$ and a working distance of $10 \mathrm{~mm}$. The wettability of produced smooth and nano-roughened fluorocarbon DCDRS substrates was determined by a home-built goniometer. It consisted of a syringe with testing liquid (liposomal suspensions), substrate holder and camera connected to a computer.

\subsection{DCDRS Measurements}

To test and compare the DCDRS performance of produced fluorocarbon-based films, the liposomal suspensions were used. These were prepared from 1,2-dipalmitoyl-snglycero-3-phosphocholine (DPPC) powder purchased from Avanti Polar Lipids. After the complete dissolution of lipid in pure chloroform in a glass flask, a stream of nitrogen gas was used to remove the solvent to form a thin layer of lipid spread on a glass surface. Subsequently, deionized water (18 M $\Omega$, Millipore-Q, Darmstadt, Germany) was added to 
the flask and mixed for lipid hydration and spontaneous vesicles formation. Complete hydration to cloudy liposome suspension was achieved by applying an ultrasonic bath and maintaining the suspension at a temperature of $10-15{ }^{\circ} \mathrm{C}$ above the main phase transition of DPPC $\left(41^{\circ} \mathrm{C}\right)$ for about half an hour. Apparatus LiposoFast-BasicTM (Avestin, Inc., Mannheim, Germany) with polycarbonate membrane filter with $100 \mathrm{~nm}$ pores was used to obtain a unilamellar suspension. The liposomal suspension was extruded through a membrane filter approximately thirty-five times at a temperature of $50{ }^{\circ} \mathrm{C}$. The detailed standard preparation procedure can be seen elsewhere [39]. The final concentration of liposomal suspension was $1 \mathrm{mg} / \mathrm{mL}(1.36 \mathrm{mM})$. This stock suspension was subsequently diluted to $0.5 \mathrm{mg} / \mathrm{mL}, 0.25 \mathrm{mg} / \mathrm{mL}$ and $0.125 \mathrm{mg} / \mathrm{mL}(0.68 \mathrm{mM}, 0.34 \mathrm{mM}$ and $0.17 \mathrm{mM}$, respectively) and all four concentrations were finally used for DCDRS measurements on smooth and nanostructured fluorocarbon substrates.

Liposome suspensions at all concentrations were deposited on substrates as $2 \mu \mathrm{L}$ droplets and left to dry at room temperature for about half an hour. All DCDRS spectra from ring patterns were recorded by Raman microspectrometer LabRAM HR800 (Horiba Jobin Yvon, Longjumeau, France) in the back-scattering arrangement. The Microspectrometer was equipped with 300 grooves $/ \mathrm{mm}$ grating and a nitrogen-cooled charged coupled device (CCD) for collecting the scattered light. Irradiation by He-Ne laser with excitation line at $632.8 \mathrm{~nm}$ was employed with final power on samples set to $6.4 \mathrm{~mW}$. All spectra were recorded with $400 \mu \mathrm{m}$ pinhole diameter, $100 \mu \mathrm{m}$ entrance slit width and 50× ULWD (ultra-long working distance) objective with the spectral acquisition of $60 \times 1 \mathrm{~s}$. White light images of formed, dried rings patterns were taken by using objective $5 \times$. Lateral parameters as widths and diameters of rings deposits were determined from white light images using ImageJ software. The lateral widths of the formed rings were measured at 10 randomly selected positions on the ring and the presented values correspond to the average of these measurements.

\subsection{Treatment of Measured Spectra by Factor Analysis (FA)}

The measured spectra were treated with background corrections and factor analysis by the in-house software developed by J. Palacký [40]. Factor analysis as a multivariate mathematical technique uses a singular value decomposition algorithm for reducing matrices of data to their lowest dimension [41]. The procedure consists of solving the eigenvalue equation that provides orthonormal subspectra $S_{j}(v)$, orthonormal matrix of corresponding scores $\mathrm{V}_{\mathrm{ij}}$ and a set of singular values $\mathrm{W}_{\mathrm{j}}$ (weights). A linear combination of computed subspectra can express each original measured spectrum $Y_{i}(v)$ as:

$$
\mathrm{Y}_{\mathrm{i}}(v)=\sum_{j=1}^{m} \mathrm{~W}_{\mathrm{j}} \mathrm{V}_{\mathrm{ijj}} \mathrm{S}_{\mathrm{j}}(v)
$$

The number $m$, factor dimension, is a minimal number of subspectra that are needed for the best approximation and reconstruction of measured (original) spectra. The output of FA is a set of subspectra, their statistical weights (singular values), residuals errors and normalized coefficients (scores), which indicate the relative presence of subspectra in individual spectra. To analyze measured Raman spectra, the 1st subspectrum is a weighted average of experimental spectra, and all other (second and each subsequent) subspectra reflect various spectral changes. The information from individual subspectra is independent because of their orthogonality. To obtain the factor dimension, singular values assigned to the subspectra can be used, where the significant drop in the value (several orders) is crucial. The number of values before the critical drop indicates the dimension.

\section{Results}

\subsection{Characterization of C:F Substrates}

The first step of this study was the characterization of fabricated fluorocarbon-based DCDRS platforms. As mentioned, two distinct types of surfaces for the DCDRS measure- 
ments were investigated: smooth pPTFE coatings and C:F coatings with nano-roughness induced by the presence of $\mathrm{Cu}$ Nps. The corresponding AFM images of these materials are depicted in Figure 2, where the typical height profiles of all samples and their height histograms are plotted, too. As can be seen, the pPTFE is indeed smooth with a root mean square roughness (Rms) of $0.1 \mathrm{~nm}$, while the increasing number of $\mathrm{Cu} N$ ps in the coatings results in more nanostructured character of the coatings and in a gradual increase in their roughness with the growing number of $\mathrm{Cu} \mathrm{Nps}$ in the films. According to the AFM measurements, the values of Rms were found to be $1.3 \mathrm{~nm}$ in the case of $\mathrm{NpsCu} 2$ sample and $2 \mathrm{~nm}$ in the case of sample NpsCu4. These values are comparable with previously reported values for systems with Ag nanoparticles having similar size (diameter $14 \mathrm{~nm}$ ) deposited for several minutes and overcoated with pPTFE layer (Rms $\sim 2 \mathrm{~nm}$ for $2 \mathrm{~min}$ deposition time of Ag Nps) [38].
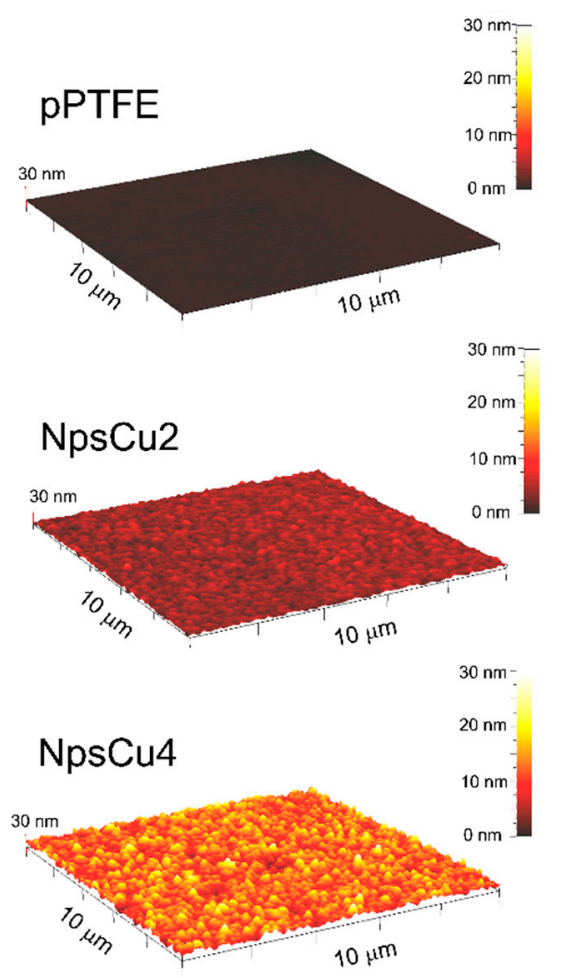

a)
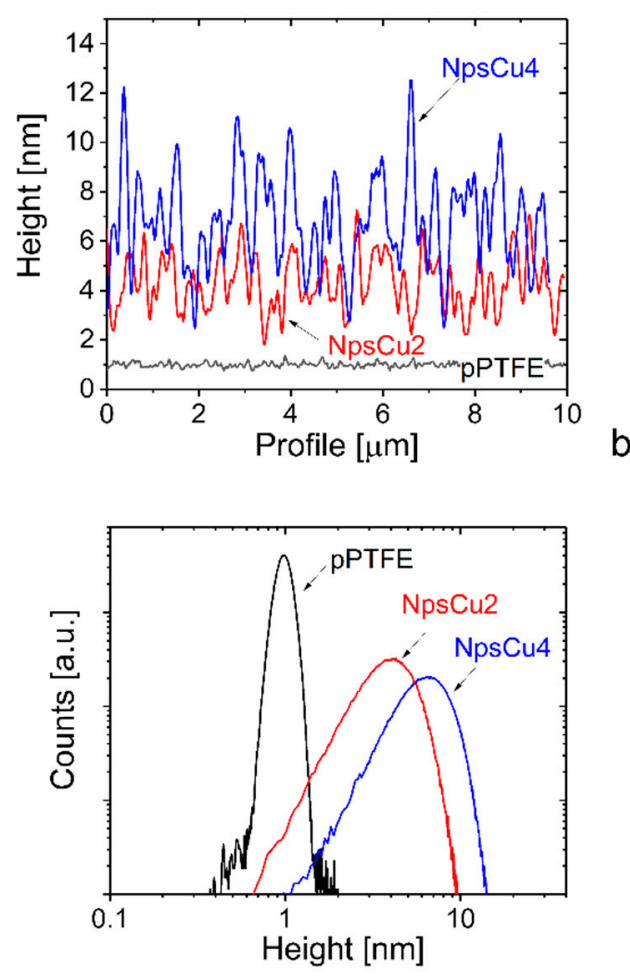

c)

Figure 2. (a) AFM images of substrates used for the DCDRS measurements together with their (b) height profiles and (c) height histograms. The height profiles and height histograms were determined from the AFM images using standard procedures in the program Gwyddion.

The nanostructured character of the samples that contain $\mathrm{Cu}$ Nps was also confirmed by SEM with clearly distinguishable $\mathrm{Cu}$ Nps (see Figure 3a). The investigation of surface nanostructures using both SE and BE modes of the scanning electron microscope revealed that the $\mathrm{Cu}$ Nps are fully coated by a C:F layer (Figure 3b). According to the measured radial profile of intensity of $\mathrm{BE}$ signal (false red) that highlights the material contrast (the higher intensity may be ascribed to the presence of $\mathrm{Cu}$ Nps in our case), the size of individual Nps is around $14 \mathrm{~nm}$. Such value corresponds to the value reported in the previous work for the $\mathrm{Cu}$ Nps prepared under similar conditions [38]. Furthermore, the thickness of the C:F overcoat deduced for the radial profile of nanostructures visualized in the SE mode (false green), i.e., in the mode that is primarily sensitive to the morphology of the samples, was found to be around $6 \mathrm{~nm}$. This value is markedly lower than the thickness of the C:F overcoat that was $20 \mathrm{~nm}$. Such difference is most likely connected with a partial penetration of pPTFE below the copper Nps due to the favored downhill current 
of the plasma polymer-forming species from the outmost surface of the Nps down to the substrate or into the inter-particle voids [42].
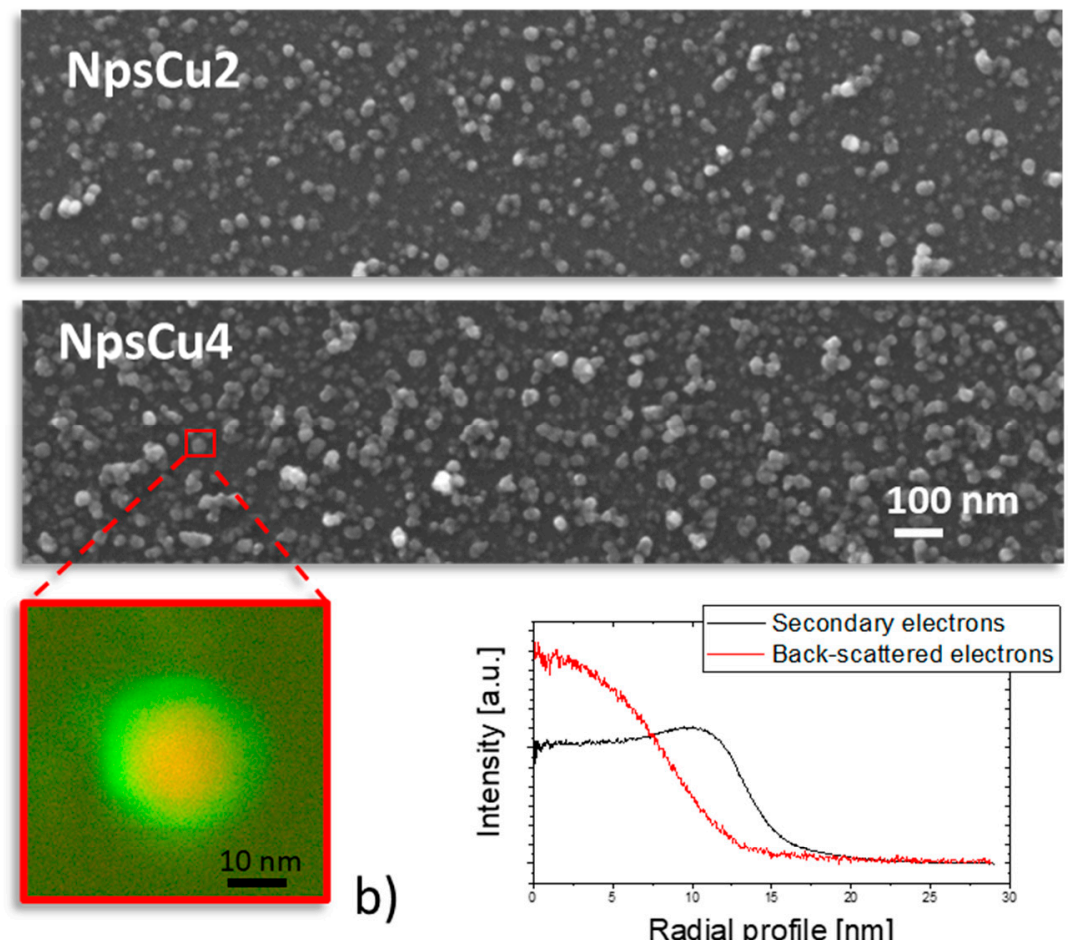

a)

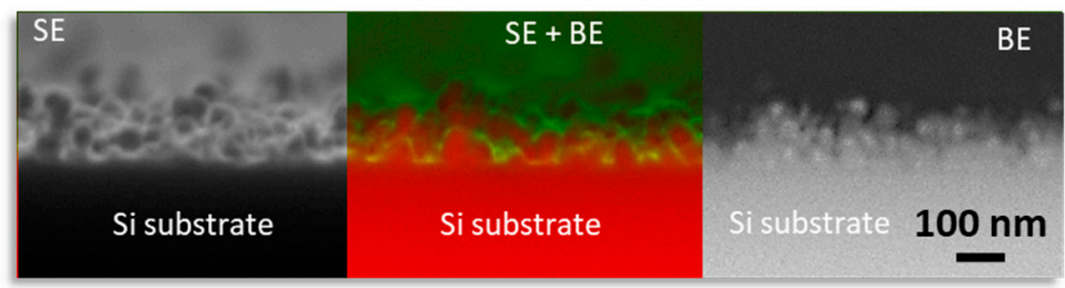

c)
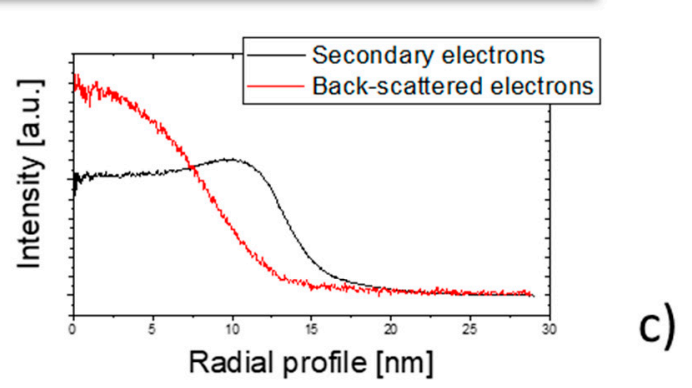

E

Figure 3. (a) Top-view SEM images of samples $\mathrm{NpsCu} 2$ and NpsCu4 measured in SE mode. (b) Composite SE (false green) and BE (false red) image of detail of surface nanostructure of sample NpsCu4 and (c) corresponding radial profiles. (d) Cross-section of NpsCu4 coatings measured in SE mode (left), BE mode (right) and composite SE and BE SEM image (middle).

\subsection{Wettability and Drying of Liposome Suspension}

A model dipalmitoylphosphatidylcholine (DPPC) was chosen to prepare a liposome suspension and subsequently to study the influence of smooth and nano-roughened substrates on the wetting/drying process of deposited samples. $2-\mu \mathrm{L}$ droplets of DPPC suspension at four concentrations $(1,0.5,0.25$ and $0.125 \mathrm{mg} / \mathrm{mL})$ were deposited on the above-mentioned substrates and left to dry at room temperature.

The first important observation is a significant increase in the initial contact angle value of deposited droplets observed with the change of smooth pPTFE substrate to the C:F substrate with deposited nanoparticles: the static contact angle increased from $108^{\circ}$ measured on smooth C:F films to $130^{\circ}$ and $135^{\circ}$ in the case of $\mathrm{NpsCu} 2$ and $\mathrm{NpsCu} 4$ samples, respectively. Such changes in surface wettability are in qualitative agreement with Wenzel's wetting model, which predicts the enhancement of hydrophobicity of hydrophobic materials upon their roughening [43]. This behavior was found to be independent of the concentration of freshly deposited suspension as the differences of the contact angles for the same substrate were always in the range $\pm 3^{\circ}$.

Next, representative white light images of the liposomal deposits after the complete evaporation of the liquid phase of the suspension presented in Figure 4 demonstrate the 
typical "coffee-ring" formation after an evaporation process for each deposited droplet on each substrate. As for smooth substrate, the evaporation process led to the formation of compact rings only for concentrations of $1 \mathrm{mg} / \mathrm{mL}$ and $0.5 \mathrm{mg} / \mathrm{mL}$ (as already observed for commercial smooth substrate SpecTRIM (Tienta Sciences, Indianapolis, IN, USA) in the study [15]). A tendency to form a ring in case of lower concentrations could also be observed. However, this had failed, and a pattern with an incomplete ring was created. This is connected with the presence of the constant contact angle (CCA) drying phase during the droplet evaporation [44] in which the triple line of the drying droplet slides on the smooth pPTFE substrate, as shown in our previous study [37]. In contrast, the heterogeneities in the $\mathrm{C}: \mathrm{F}$ surface topography induced by the presence of $\mathrm{Cu} \mathrm{Nps}$ lead to the suppression of the CCA drying phase. Thus, the droplet stays pinned on the surface during its evaporation. The droplet pinning, in turn, allows for the formation of complete and well-defined rings after the complete droplet evaporation also for the lower concentrations.

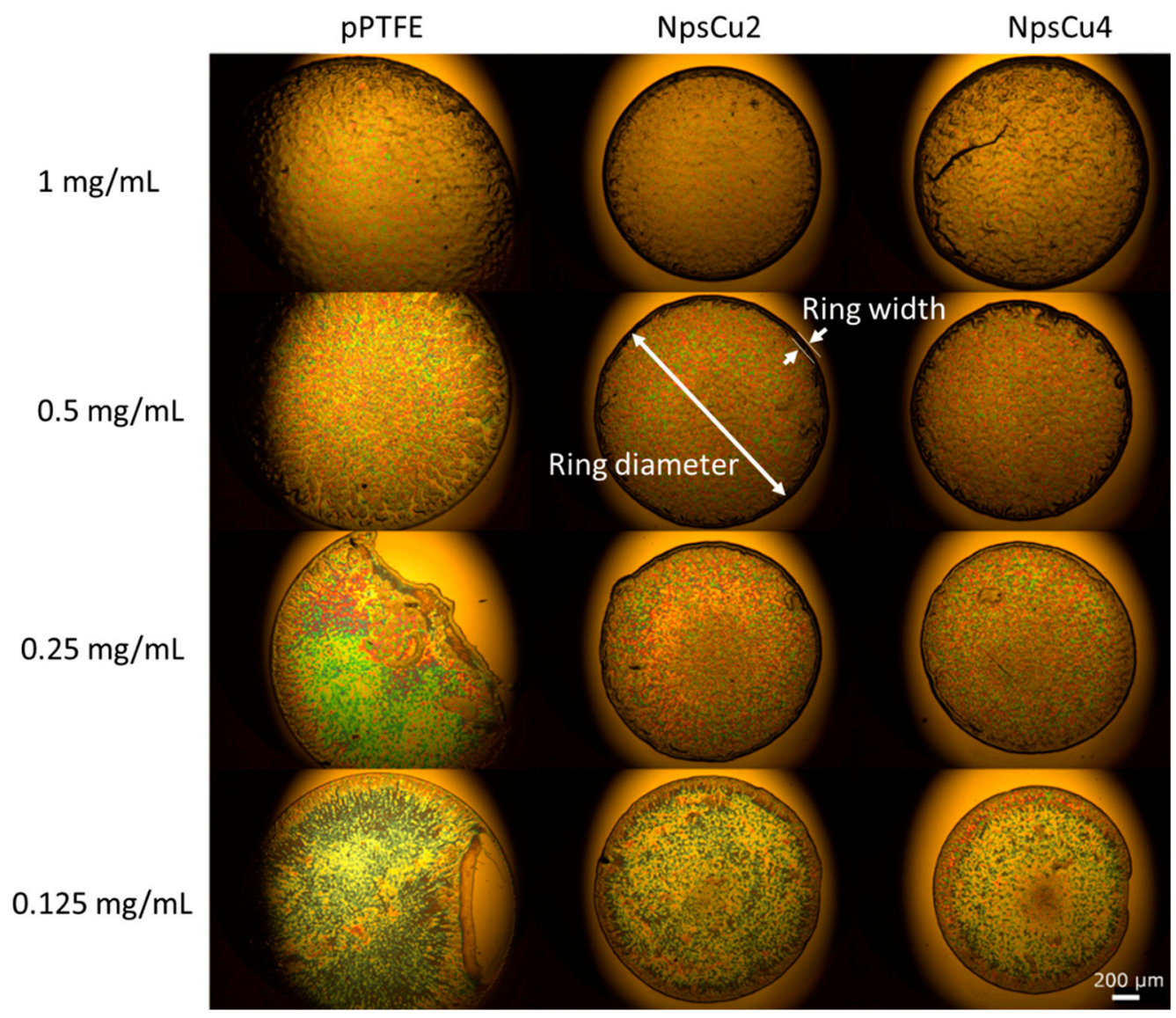

Figure 4. White light images of formed patterns after evaporation of DPPC liposome suspension at four concentrations on three different substrates.

Another effect visible in Figure 4 and quantitatively summarized in Figure 5 is a decrease in the mean diameters and widths of rings formed after the droplet evaporation. As the hydrophobicity and thus also the contact angle increased, the initial contact radius for the droplets with the same volume had to decrease. Because of this, the diameter of the dried DPPC ring decreased in all cases as the wettability decreased. Furthermore, it was found that the initial concentration of the deposited droplet influenced the final structure of the dried pattern, namely the width of the formed ring: deposited drops of lower concentrations dried out into the patterns with a narrower width of the final ring, as shown in Figure 5. This phenomenon is supposed to be connected with the lower number of liposomes that may form the ring. It was also observed that greater roughening (in the 
case of $\mathrm{NpsCu} 4$ ) did not cause a more pronounced decrease in the diameters and widths of the formed rings, which is consistent with similar wettability of both samples.

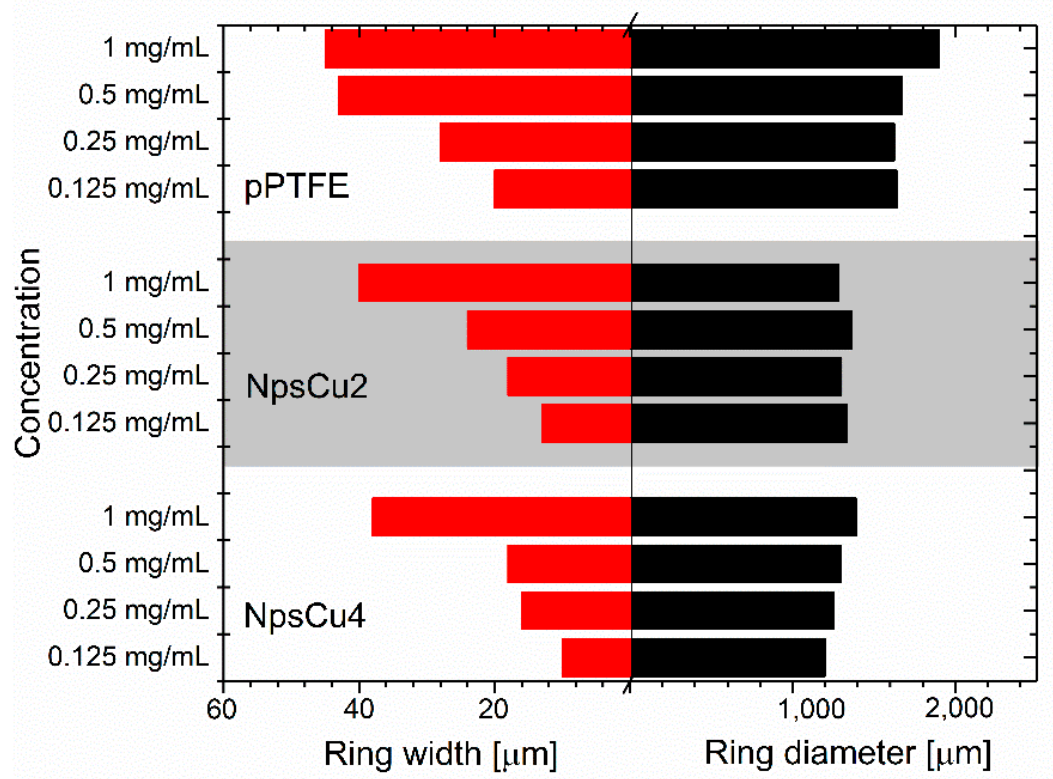

Figure 5. Lateral widths and diameters of the rings formed after the DPPC liposome suspension evaporation.

\subsection{DCDRS Performance}

Polymeric fluorocarbon smooth surface (pPTFE) was used for testing DCDRS performance of dropped samples of liposomal suspension at different concentrations. For each dried deposit, 25 Raman spectra over the whole ring were accumulated. Acquired spectra for each concentration were treated by baseline adjustment procedure using inhouse software to eliminate background signal variations [40]. A typical example of the whole measured spectral interval $550-3300 \mathrm{~cm}^{-1}$ for DPPC liposomes by DCDRS on pPTFE substrate is presented in Figure 6a. The upper region $2600-3200 \mathrm{~cm}^{-1}$ shown in Figure $6 \mathrm{~b}$ represents the dominant, more intense part corresponding to the $\mathrm{C}-\mathrm{H}$ stretching vibrations. Specifically, the spectral band of $2850 \mathrm{~cm}^{-1}$ is assigned to the $\mathrm{C}-\mathrm{H}$ symmetric stretching, $2885 \mathrm{~cm}^{-1}$ to the $\mathrm{C}-\mathrm{H}$ antisymmetric stretching, and the shoulder at $2936 \mathrm{~cm}^{-1}$ corresponds to terminal $\mathrm{CH}_{3}$ symmetric stretching vibrations. The lower part $550-1800 \mathrm{~cm}^{-1}$ is less intense and can be more affected by the background signal during the measurement. The three spectral bands in the $1000-1150 \mathrm{~cm}^{-1}$ region are assigned to $C-C$ stretching, the band $1299 \mathrm{~cm}^{-1}$ is assigned to the $\mathrm{CH}_{2}$ twisting and the signal at $1441 \mathrm{~cm}^{-1}$ corresponds to $\mathrm{CH}_{2}$ bending $[17,45,46]$. To compare the signal for different concentrations, the dominant part of spectra sensitive to the phase transitions changes or conceivable interaction with the substrate was used [46]. After the background correction, the averaged spectra for each concentration were compared as shown in Figure $6 b$, where a decrease of the signal with concentration is clearly demonstrated. This confirms that polymeric fluorocarbon smooth substrate can serve as a suitable hydrophobic DCDRS substrate for liposomal suspension. 


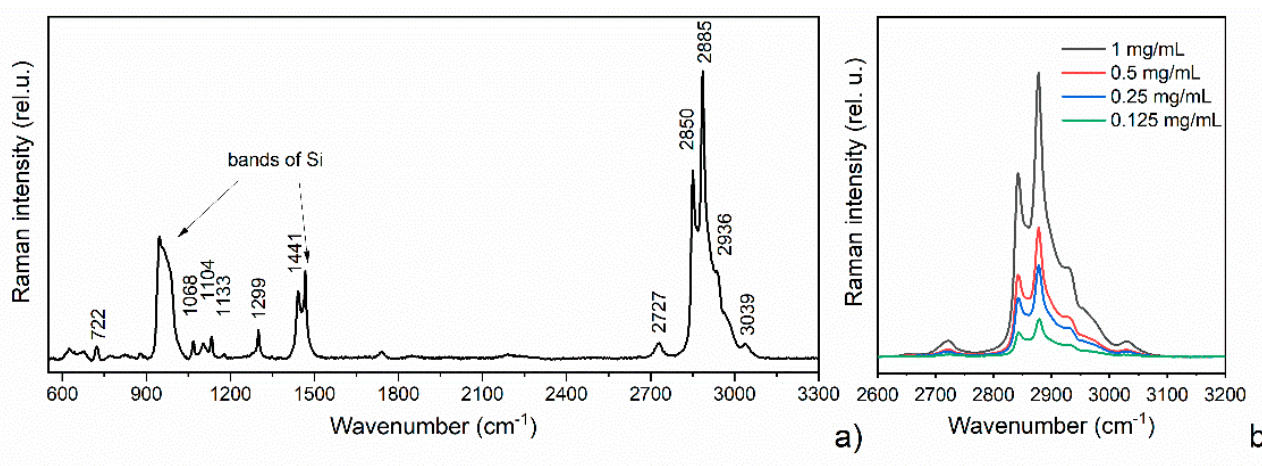

Figure 6. DCDRS spectra of dried liposome suspension from ring-shaped pattern on smooth pPTFE substrate (a) at DPPC concentration of $1 \mathrm{mg} / \mathrm{mL}$ in the spectral interval $550-3300 \mathrm{~cm}^{-1}$. Marked bands of Si originate from the base layer of the substrate; and (b) comparison for the upper dominant region at four different concentrations.

Afterwards, the DCDRS performance of nano-roughened hydrophobic surfaces (NpsCu2 and NpsCu4) for the same samples of liposomal suspension was studied and compared to the performance of the smooth pPTFE substrate. In total, 5 DCDRS spectra were accumulated similarly as for the pPTFE substrate focusing on the dominant part of spectra 2600-3200 $\mathrm{cm}^{-1}$. The baseline-corrected spectra were averaged for each concentration and substrate and compared to each other, as shown in Figure 7. Obtained results showed that the intensity of DPPC spectral bands for each concentration varied in the case of the nanostructured substrates with $\mathrm{Cu} N$ ps. For lower concentrations $(0.5 \mathrm{mg} / \mathrm{mL}$ and $0.125 \mathrm{mg} / \mathrm{mL}$ ) only a minor intensity difference is present for both nanostructured substrates. At $1 \mathrm{mg} / \mathrm{mL}$, the averaged spectrum from $\mathrm{NpsCu} 4$ is more intense than from $\mathrm{NpsCu} 2$, but at $0.25 \mathrm{mg} / \mathrm{mL}$ the performance from $\mathrm{NpsCu} 2$ is better.
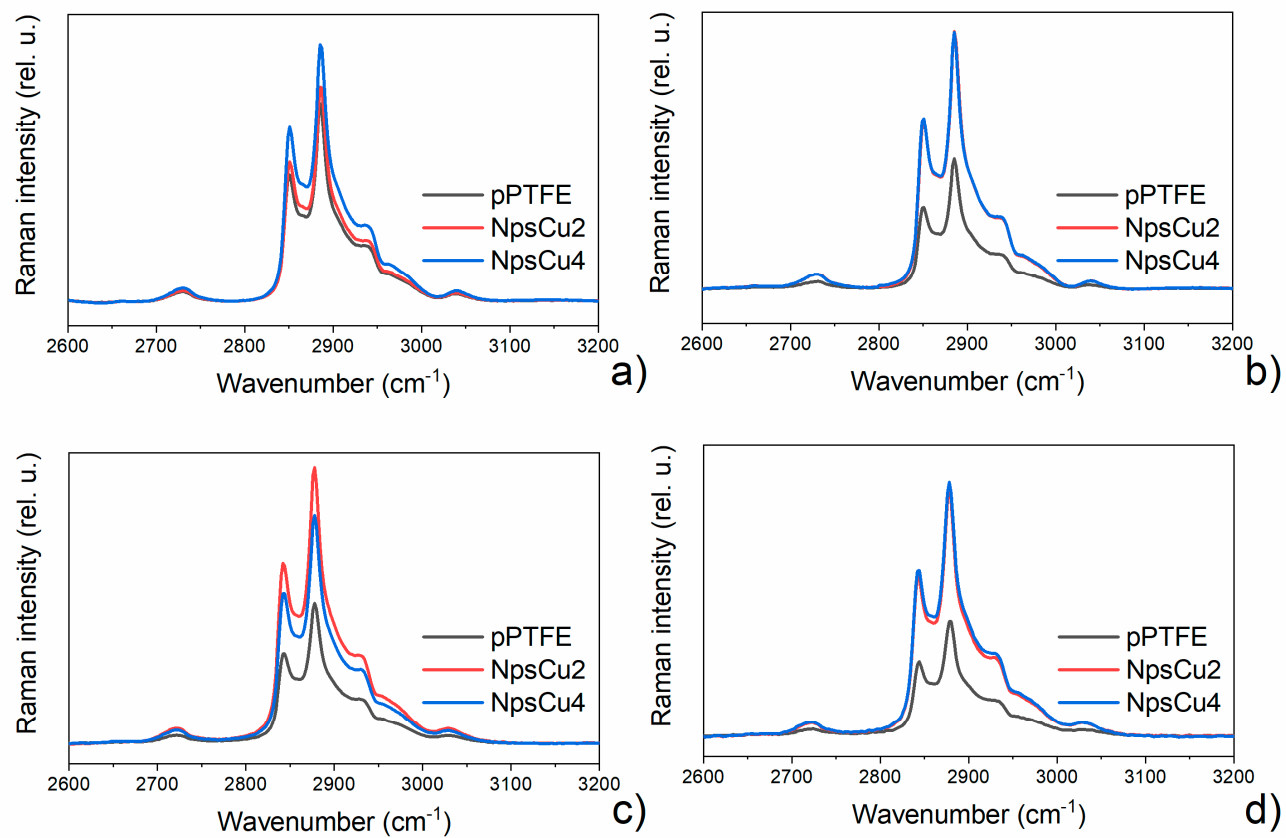

Figure 7. Averaged spectra (baseline corrected) for (a) $1 \mathrm{mg} / \mathrm{mL}$, (b) $0.5 \mathrm{mg} / \mathrm{mL}$, (c) $0.25 \mathrm{mg} / \mathrm{mL}$ and (d) $0.125 \mathrm{mg} / \mathrm{mL}$ deposited concentration of DPPC in the form of liposome suspension.

To demonstrate the DCDRS performance of smooth versus nanostructured substrates, integral intensities in the region $2780-3020 \mathrm{~cm}^{-1}$ were calculated. These values, as well as the increase in intensity (in \%), are summarized in Figure 8. The significant about twofold increase in integral intensity for nanostructured $\mathrm{NpsCu} 2$ substrate relative to the pPTFE 
one at a concentration of $0.5,0.25$ and $0.125 \mathrm{mg} / \mathrm{mL}$ when increased by 105,97 and $114 \%$, respectively, is clearly seen. Unlike in the case of the concentration $1 \mathrm{mg} / \mathrm{mL}$ this increase is only by $10 \%$. Moreover, these results show that the relevant improvement is achieved when the smooth pPTFE substrate is replaced by the nano-roughened $\mathrm{NpsCu} 2$, but the additional increase in deposited nanoparticles (NpsCu4) does not guarantee even better performance. The mechanism is based on a more efficient preconcentration of the liposomes from suspension into the dried ring deposit due to the nano-roughened substrate.

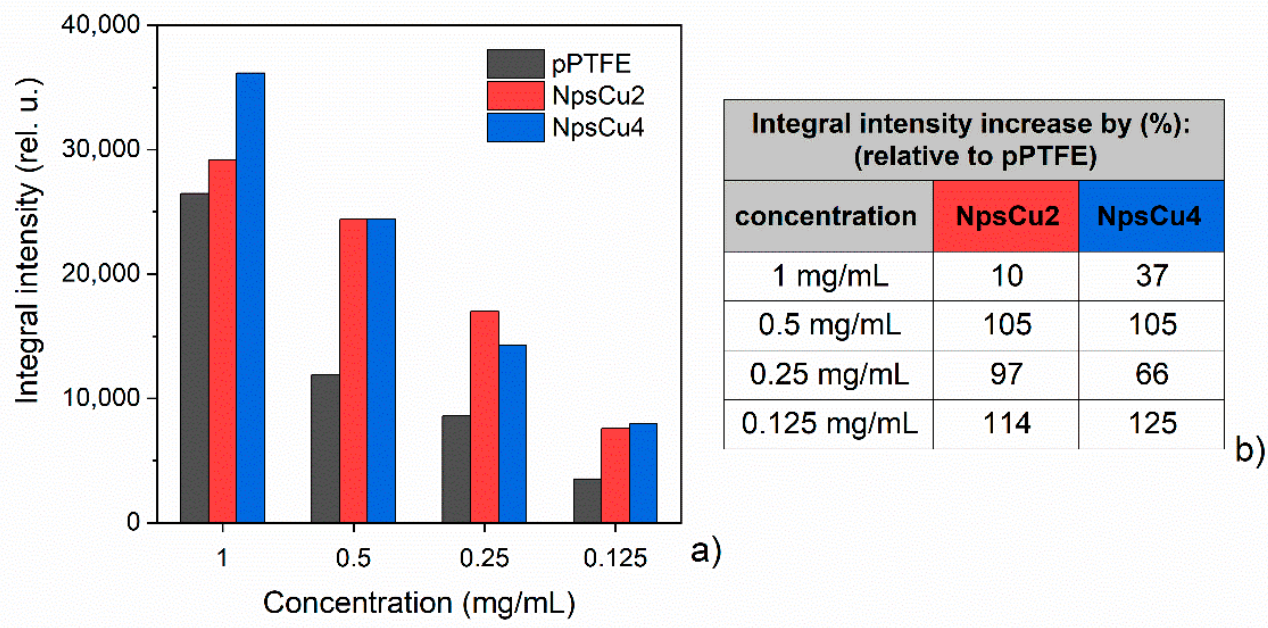

Figure 8. (a) Comparison of the integral intensity of averaged DPPC spectra in the region 2780-3020 $\mathrm{cm}^{-1}$ for smooth pPTFE and nanorough NpsCu2, NpsCu4 substrates with (b) the integral intensity increase (in \%) for nanostructured substrates relative to the smooth pPTFE substrate.

The previous comparison of averaged spectra illustrates only the intensity difference but does not give any information of possible changes in spectral shape due to the side effects, such as an interaction of DPPC with the substrate. A factor analysis (FA) was therefore used as a suitable tool for better determination of the performance for employed hydrophobic substrates. This robust treatment can show (across the different substrates) if any other than intensity changes are present in measured spectral sets. One spectral set for FA consisted of 75 spectra in total, 25 spectra for each substrate.

Due to the nature of the studied system, we expected that the factor dimension would be one. In this case, no change in spectral shape caused by phase transition or interaction between DPPC and substrate would be present, and only intensity variations could be observable. The FA results (seen in Figure 9 for an example of FA performed for the concentration of $0.5 \mathrm{mg} / \mathrm{mL}$ ) showed that the factor dimension is indeed equal to 1 as the singular values $(\mathrm{W})$ representing the statistical weight of the spectral component decreased significantly for the second and higher components. Furthermore, the residual errors do not have any significant drop, which implies that the first subspectrum with its scores is sufficient to describe our original set of spectra, and including the second or higher subspectrum does not lower the overall residual error significantly. 

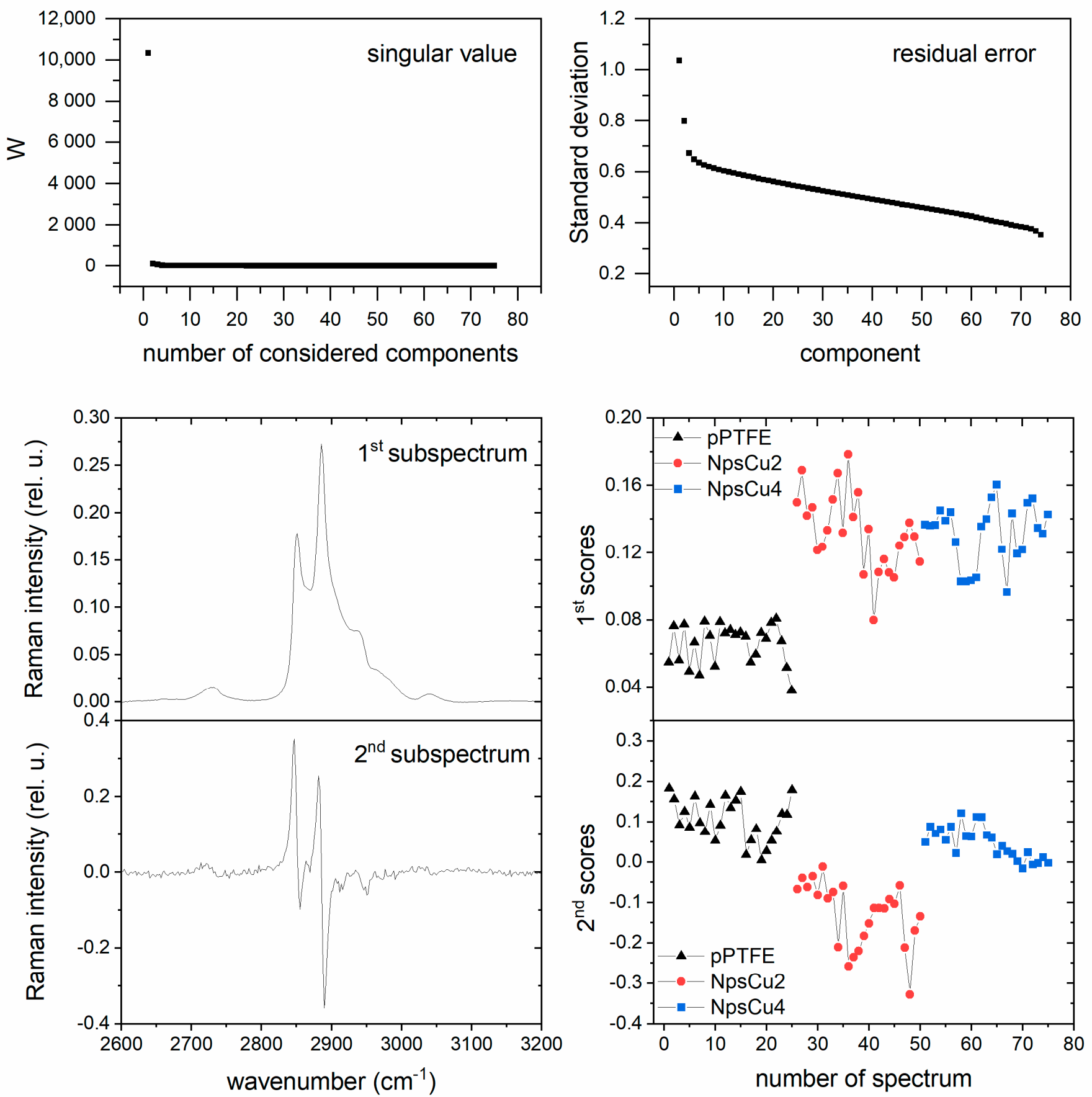

Figure 9. Results of FA for deposited liposome suspension at concentration of $0.5 \mathrm{mg} / \mathrm{mL}$ of DPPC, in the particular singular value assigned as $\mathrm{W}$, standard deviation, first and second subspectrum and their belonging scores.

The first subspectrum represents the spectral shape of the DPPC liposome spectrum for the selected spectral interval, and sets of coefficients (scores) belonging to it represent the overall Raman intensity for each baseline-corrected spectrum. From the scores belonging to the first subspectrum concentration, it can be seen that coefficients increase when changing the smooth pPTFE substrate to the nanostructured substrates. As for the second subspectrum, its peculiar shape can be produced by the external effect of calibration due to the laser line shifting during the measurements and by the background signal. Similar results, i.e., the shape of the first and second subspectra, relevant statistical weights and residual errors were also achieved for other studied concentrations. Thus, we can 
conclude that we observe only changes in the intensities of the Raman signal due to the preconcentration and the interaction of the liposomes with the surface does not occur.

\section{Conclusions}

DCDRS appeared recently to be a highly promising tool for biodetection. The main advantages of this technique are its simplicity and the possibility to analyze samples at biologically relevant concentrations. However, further improvement of the detection capabilities of DCDRS is still needed. While previous studies employed smooth DCDRS substrates, in this study, we propose and investigate for the first time a novel platform for DCDRS measurements based on the nanostructured C:F plasma polymer coatings fabricated by means of the vacuum-based and fully solvent-free procedure. This technique was found to enable the fabrication of C:F films with tailor-made surface properties relevant for the DCDRS (roughness and wettability). In order to highlight the advantages of nanostructuring, the performance of nanostructured C:F films are compared with smooth C:F films with the same surface chemical composition. The main results may be summarized as follows:

- The smooth C:F surfaces deposited by magnetron sputtering were found to be suitable for the DCDRS detection of liposomes. This is due to the hydrophobic character of C:F coatings that forces liquid liposome suspensions to form coffee-ring structures after the complete evaporation of the liquid phase, at least at a higher DPPC concentration.

- As it is shown, the DCDRS measurements might be significantly improved when the fluorocarbon coatings are nanostructured. This led not only to the pinning of the drying droplet that allowed for the formation of well-defined rings also in the case of lower DPPC concentration but also to the lowering the diameter of the resulting rings. The latter, in turn, made it possible to reach a higher concentration of liposomes in the rings and, hence, to get two times higher Raman signal intensity as compared to smooth fluorocarbon films without compromising the profile of recorded Raman spectra.

- These findings may pave the way for the development of cheap and disposable platforms for efficient DCDRS-based biodetection.

Author Contributions: Conceptualization, A.K. (Alžbeta Kuižová) and E.K.; investigation, A.K. (Alžbeta Kuižová), A.K. (Anna Kuzminova), E.K. and O.K.; writing-original draft preparation, A.K. (Alžbeta Kuižová); writing—review and editing, O.K.; supervision, E.K. All authors have read and agreed to the published version of the manuscript.

Funding: This research was funded by the Czech Science Foundation, grant number 18-10897S, Charles University Research Centre program UNCE/SCI/01 and Grant Agency of Charles University, grant number GA UK (290120).

Institutional Review Board Statement: Not applicable.

Informed Consent Statement: Not applicable.

Data Availability Statement: The data presented in this study are available on request from the corresponding authors.

Conflicts of Interest: The authors declare no conflict of interest.

\section{References}

1. Li, S.; Huang, J.; Chen, Z.; Chen, G.; Lai, Y. A review on special wettability textiles: Theoretical models, fabrication technologies and multifunctional applications. J. Mater. Chem. A 2017, 5, 31-55. [CrossRef]

2. van Osch, T.H.J.; Perelaer, J.; de Laat, A.W.M.; Schubert, U.S. Inkjet Printing of Narrow Conductive Tracks on Untreated Polymeric Substrates. Adv. Mater. 2008, 20, 343-345. [CrossRef]

3. Su, X.; Li, X.; Ong, C.Y.A.; Herng, T.S.; Wang, Y.; Peng, E.; Ding, J. Metallization of 3D Printed Polymers and Their Application as a Fully Functional Water-Splitting System. Adv. Sci. 2019, 6, 1801670. [CrossRef]

4. Ferreira, P.; Alves, P.; Coimbra, P.; Gil, M.H. Improving polymeric surfaces for biomedical applications: A review. J. Coat. Technol. Res. 2015, 12, 463-475. [CrossRef] 
5. Kim, M.S.; Khang, G.; Lee, H.B. Gradient polymer surfaces for biomedical applications. Prog. Polym. Sci. 2008, 33, 138-164. [CrossRef]

6. van Wachem, P.B.; Beugeling, T.; Feijen, J.; Bantjes, A.; Detmers, J.P.; van Aken, W.G. Interaction of cultured human endothelial cells with polymeric surfaces of different wettabilities. Biomaterials 1985, 6, 403-408. [CrossRef]

7. Lee, J.H.; Khang, G.; Lee, J.W.; Lee, H.B. Interaction of Different Types of Cells on Polymer Surfaces with Wettability Gradient. J. Colloid Interface Sci. 1998, 205, 323-330. [CrossRef]

8. Bacakova, L.; Filova, E.; Parizek, M.; Ruml, T.; Svorcik, V. Modulation of cell adhesion, proliferation and differentiation on materials designed for body implants. Biotechnol. Adv. 2011, 29, 739-767. [CrossRef]

9. Cai, S.; Wu, C.; Yang, W.; Liang, W.; Yu, H.; Liu, L. Recent advance in surface modification for regulating cell adhesion and behaviors. Nanotechnol. Rev. 2020, 9, 971-989. [CrossRef]

10. Mampallil, D.; Eral, H.B. A review on suppression and utilization of the coffee-ring effect. Adv. Colloid Interface Sci. 2018, 252, 38-54. [CrossRef]

11. Parsa, M.; Harmand, S.; Sefiane, K. Mechanisms of pattern formation from dried sessile drops. Adv. Colloid Interface Sci. 2018, 254, 22-47. [CrossRef] [PubMed]

12. Zang, D.; Tarafdar, S.; Tarasevich, Y.Y.; Dutta Choudhury, M.; Dutta, T. Evaporation of a Droplet: From physics to applications. Phys. Rep. 2019, 804, 1-56. [CrossRef]

13. Deegan, R.D.; Bakajin, O.; Dupont, T.F.; Huber, G.; Nagel, S.R.; Witten, T.A. Capillary flow as the cause of ring stains from dried liquid drops. Nature 1997, 389, 827-829. [CrossRef]

14. Zhang, D.; Xie, Y.; Mrozek, M.F.; Ortiz, C.; Davisson, V.J.; Ben-Amotz, D. Raman Detection of Proteomic Analytes. Anal. Chem. 2003, 75, 5703-5709. [CrossRef]

15. Kopecký, V.; Baumruk, V. Structure of the ring in drop coating deposited proteins and its implication for Raman spectroscopy of biomolecules. Vib. Spectrosc. 2006, 42, 184-187. [CrossRef]

16. Kočišová, E.; Procházka, M. Drop-coating deposition Raman spectroscopy of porphyrins. J. Raman Spectrosc. 2015, 46, 280-282. [CrossRef]

17. Kočišová, E.; Procházka, M. Drop-coating deposition Raman spectroscopy of liposomes. J. Raman Spectrosc. 2011, 42, 1606-1610. [CrossRef]

18. Šimáková, P.; Kocisová, E.; Procházka, M. Sensitive Raman spectroscopy of lipids based on drop deposition using DCDR and SERS. J. Raman Spectrosc. 2013, 44, 1479-1482. [CrossRef]

19. Kočišová, E.; Procházka, M. Drop coating deposition Raman spectroscopy of dipicolinic acid. J. Raman Spectrosc. 2018, 49, 2050-2052. [CrossRef]

20. Mrozek, M.F.; Zhang, D.; Ben-Amotz, D. Oligosaccharide identification and mixture quantification using Raman spectroscopy and chemometric analysis. Carbohydr. Res. 2004, 339, 141-145. [CrossRef]

21. Kuižová, A.; Přikryl, M.; Procházka, M.; Kočišová, E. Drop coating deposition Raman (DCDR) spectroscopy of contaminants. Spectrochim. Acta Part A Mol. Biomol. Spectrosc. 2021, 262, 120109. [CrossRef] [PubMed]

22. Filik, J.; Stone, N. Analysis of human tear fluid by Raman spectroscopy. Anal. Chim. Acta 2008, 616, 177-184. [CrossRef]

23. Filik, J.; Stone, N. Investigation into the protein composition of human tear fluid using centrifugal filters and drop coating deposition Raman spectroscopy. J. Raman Spectrosc. 2009, 40, 218-224. [CrossRef]

24. Hu, P.; Zheng, X.-S.; Zong, C.; Li, M.-H.; Zhang, L.-Y.; Li, W.; Ren, B. Drop-coating deposition and surface-enhanced Raman spectroscopies (DCDRS and SERS) provide complementary information of whole human tears. J. Raman Spectrosc. 2014, 45, 565-573. [CrossRef]

25. Dingari, N.C.; Horowitz, G.L.; Kang, J.W.; Dasari, R.R.; Barman, I. Raman Spectroscopy Provides a Powerful Diagnostic Tool for Accurate Determination of Albumin Glycation. PLoS ONE 2012, 7, e32406. [CrossRef]

26. Abdolahzadeh, S.; Boyle, N.M.; Draksharapu, A.; Dennis, A.C.; Hage, R.; de Boer, J.W.; Browne, W.R. Off-line reaction monitoring of the oxidation of alkenes in water using drop coating deposition Raman (DCDR) spectroscopy. Analyst 2013, 138, 3163-3171. [CrossRef] [PubMed]

27. Xie, Y.; Jiang, Y.; Ben-Amotz, D. Detection of amino acid and peptide phosphate protonation using Raman spectroscopy. Anal. Biochem. 2005, 343, 223-230. [CrossRef]

28. Kočišová, E.; Procházka, M.; Vaculčiaková, L. Drop-Coating Deposition Raman (DCDR) Spectroscopy as a Tool for Membrane Interaction Studies: Liposome-Porphyrin Complex. Appl. Spectrosc. 2015, 69, 939-945. [CrossRef]

29. Zhang, D.; Mrozek, M.F.; Xie, Y.; Ben-Amotz, D. Chemical Segregation and Reduction of Raman Background Interference Using Drop Coating Deposition. Appl. Spectrosc. 2004, 58, 929-933. [CrossRef]

30. Filik, J.; Stone, N. Drop coating deposition Raman spectroscopy of protein mixtures. Analyst 2007, 132, 544-550. [CrossRef]

31. Prochazka, M. Surface-Enhanced Raman Spectroscopy. Bioanalytical, Biomolecular and Medical Applications, 1st ed.; Springer: Cham, Switzerland, 2016; pp. 1-221.

32. Mosier-Boss, P.A. Review of SERS Substrates for Chemical Sensing. Nanomaterials 2017, 7, 142. [CrossRef] [PubMed]

33. Pilot, R.; Signorini, R.; Durante, C.; Orian, L.; Bhamidipati, M.; Fabris, L. A Review on Surface-Enhanced Raman Scattering. Biosensors 2019, 9, 57. [CrossRef] [PubMed] 
34. Kocisova, E.; Petr, M.; Sipova, H.; Kylian, O.; Prochazka, M. Drop coating deposition of a liposome suspension on surfaces with different wettabilities: "Coffee ring" formation and suspension preconcentration. Phys. Chem. Chem. Phys. 2017, 19, 388-393. [CrossRef] [PubMed]

35. Kylián, O.; Polonskyi, O.; Kratochvíl, J.; Artemenko, A.; Choukourov, A.; Drábik, M.; Solař, P.; Slavínská, D.; Biederman, H. Control of Wettability of Plasma Polymers by Application of Ti Nano-Clusters. Plasma Process. Polym. 2012, 9, 180-187. [CrossRef]

36. Kylián, O.; Petr, M.; Serov, A.; Solař, P.; Polonskyi, O.; Hanuš, J.; Choukourov, A.; Biederman, H. Hydrophobic and superhydrophobic coatings based on nanoparticles overcoated by fluorocarbon plasma polymer. Vacuum 2014, 100, 57-60. [CrossRef]

37. Kratochvíl, J.; Kuzminova, A.; Solař, P.; Hanuš, J.; Kylián, O.; Biederman, H. Wetting and drying on gradient-nanostructured $\mathrm{C}:$ F surfaces synthesized using a gas aggregation source of nanoparticles combined with magnetron sputtering of polytetrafluoroethylene. Vacuum 2019, 166, 50-56. [CrossRef]

38. Haberland, H.; Karrais, M.; Mall, M.; Thurner, Y. Thin films from energetic cluster impact: A feasibility study. J. Vac. Sci. Technol. A 1992, 10, 3266-3271. [CrossRef]

39. MacDonald, R.; Macdonald, R.; Menco, B.; Takeshita, K.; Subbarao, N.; Hu, L.-r. Small-Volume Extrusion Apparatus for Preparation of Large, Unilamellar Vesicles. Biochim. Biophys. Acta 1991, 1061, 297-303. [CrossRef]

40. Palacký, J.; Mojzeš, P.; Bok, J. SVD-based method for intensity normalization, background correction and solvent subtraction in Raman spectroscopy exploiting the properties of water stretching vibrations. J. Raman Spectrosc. 2011, 42, 1528-1539. [CrossRef]

41. Malinowski, E.R. Factor Analysis in Chemistry, 3rd ed.; Wiley: New York, NY, USA, 2002.

42. Choukourov, A.; Kylian, O.; Petr, M.; Vaidulych, M.; Nikitin, D.; Hanus, J.; Artemenko, A.; Shelemin, A.; Gordeev, I.; Kolska, Z.; et al. RMS roughness-independent tuning of surface wettability by tailoring silver nanoparticles with a fluorocarbon plasma polymer. Nanoscale 2017, 9, 2616-2625. [CrossRef]

43. Wenzel, R.N. Resistance of Solid Surfaces to Wetting by Water. Ind. Eng. Chem. 1936, 28, 988-994. [CrossRef]

44. Pittoni, P.G.; Chang, C.-C.; Yu, T.-S.; Lin, S.-Y. Evaporation of water drops on polymer surfaces: Pinning, depinning and dynamics of the triple line. Colloids Surf. A Physicochem. Eng. Asp. 2013, 432, 89-98. [CrossRef]

45. Czamara, K.; Majzner, K.; Pacia, M.Z.; Kochan, K.; Kaczor, A.; Baranska, M. Raman spectroscopy of lipids: A review. J. Raman Spectrosc. 2015, 46, 4-20. [CrossRef]

46. Levin, I.W. Vibrational spectroscopy of membrane assemblies. In Advances in Infrared and Raman Sepctroscopy, 1st ed.; Clark, R.J.H., Hester, R.E., Eds.; Wiley: New York, NY, USA, 1984; Volume 12, p. 48. 